\title{
Deceased Organ Transplantation in Bangladesh: The Dynamics of Bioethics, Religion and Culture
}

\author{
Md. Sanwar Siraj ${ }^{1}$ (D)
}

Accepted: 17 December 2020 / Published online: 17 February 2021

(c) The Author(s), under exclusive licence to Springer Nature B.V. part of Springer Nature 2021

\begin{abstract}
Organ transplantation from living related donors in Bangladesh first began in October 1982, and became commonplace in 1988. Cornea transplantation from posthumous donors began in 1984 and living related liver and bone marrow donor transplantation began in 2010 and 2014 respectively. The Human Organ Transplantation Act officially came into effect in Bangladesh on 13th April 1999, allowing organ donation from both brain-dead and related living donors for transplantation. Before the legislation, religious leaders issued fatwa, or religious rulings, in favor of organ transplantation. The Act was amended by the Parliament on 8th January, 2018 with the changes coming into effect shortly afterwards on 28th January. However, aside from a few posthumous corneal donations, transplantation of vital organs, such as the kidney, liver, heart, pancreas, and other body parts or organs from deceased donors, has remained absent in Bangladesh. The major question addressed in this article is why the transplantation of vital organs from deceased donors is absent in Bangladesh. In addition to the collection of secondary documents, interviews were conducted with senior transplant physicians, patients and their relatives, and the public, to learn about posthumous organ donation for transplantation. Interviews were also conducted with a medical student and two grief counselors to understand the process of counseling the families and obtaining consent to obtain posthumous cornea donations from brain-dead patients. An interview was conducted with a professional anatomist to understand the processes behind body donation for the purposes of medical study and research. Their narrative reveals that transplant physicians may be reticent to declare brain death as the stipulations of the 1999 act were unclear and vague. This study finds that Bangladeshis have strong family ties and experience anxiety around permitting separating body parts of dead relatives for organ donation for transplantation, or donating the dead body for medical study and research purposes. Posthumous organ donation for transplantation is commonly viewed as a wrong deed from a religious point of view. Religious scholars who have been consulted by the government have approved posthumous organ donation for transplantation on the grounds of necessity to save lives even though violating the human body is generally forbidden in Islam. An assessment of the dynamics
\end{abstract}

Extended author information available on the last page of the article 
of biomedicine, religion and culture leads to the conclusion that barriers to posthumous organ donation for transplantation that are perceived to be religious may actually stem from cultural attitudes. The interplay of faith, belief, religion, social norms, rituals and wider cultural attitudes with biomedicine and posthumous organ donation and transplantation is very complex. Although overcoming the barriers to organ donation for transplantation is challenging, initiation of transplantation of vital organs from deceased donors is necessary within Bangladesh. This will ensure improved healthcare outcomes, prevent poor people from being coerced into selling their organs to rich recipients, and protect the solidarity and progeny of Bangladeshi families.

Keywords Deceased donation · Organ transplantation · Islam · Culture · Bioethics · Bangladesh

\section{Introduction}

The government of Bangladesh is constitutionally committed to provide primary healthcare services and the associated logistics to the people through public hospitals (Article 15: GoB 1972). The government faces challenges in providing basic healthcare services to the vast majority of its population, as nearly $63 \%$ live in rural areas (The World Bank 2019) and more than 20\% live below the poverty line (Asian Development Bank 2020). However, allocation in the state budget for health care is insufficient as less than $2.5 \%$ of the nation's Gross Domestic Product (GDP) is spent on the health sector (Islam 2014; The World Bank 2017). This is low, even in comparison to other socio-economically similar countries in South Asia, for example, Nepal, which spends roughly $5.5 \%$ of its GDP on healthcare, while Maldives spends more than 9\% (The World Bank 2017). Tertiary healthcare services, such as organ transplantation, still do not rank as high priority in Bangladesh. The majority of healthcare funds have been allocated to primary healthcare services, because the government of Bangladesh is committed to providing basic healthcare services to the vast majority of the population free of cost or at subsidized prices (GoB 2018).

The exact rate of end-stage vital organ failure is unknown because there is no national database in Bangladesh (Rashid 2004; Siraj 2016). It is known from different sources that around 20,000,000 Bangladeshis currently suffer from kidney related diseases, and another 500,000 suffer from corneal diseases (Rahman and Mahmood 2017). Of these kidney disease patients, nearly 800,000 have end-stage kidney failure while 40,000 die every year due to failures associated with dialysis or organ transplants (Palma 2017). Fifty-four kidney disease patients die every day due to a lack of transplant organs in Bangladesh (The Independent 2020). A rough estimation suggests that only 130 end-stage renal failure patients obtain kidney transplantations compared to an estimated 5,000 who need them annually (Ali 2012). Consequently, a huge number of end-stage renal failure patients die annually without receiving organ transplantations in Bangladesh. 
Organ transplantation has emerged as a lifesaving medical intervention which is medically suitable for end-stage organ failure patients. The first successful kidney transplant in Bangladesh was performed in October 1982 and it was regularized as a medical practice in 1988 (Ali 2012). Nearly 2000 kidneys have been transplanted throughout the country (Prothom 2020). Liver transplantation began in 2010. A total of six liver transplantations from living related donors have been successfully performed in the country (Rashid 2018b). Bone marrow transplantation was initiated in 2014, and a total of 25 bone marrow transplantations from living related donors have been successfully performed in Bangladesh (bdnews24.com 2017). Although liver and bone marrow transplantation from living related donors does occur in Bangladesh, kidneys are still the most commonly transplanted organs.

Cornea transplantation from deceased donors began in Bangladesh as early as 1984 (Haider 2007). Nearly 1,500,000 people suffer from blindness, among them 526,000 due to cornea defects (SNEDS 2020). The government of Bangladesh passed the Blind Relief (Donation of Eye) act in July 1975 to address the problem of blindness in the country (GoB 1975). Donated corneas have been collected and used for transplantation following the 1975 act. The Sandhani National Eye Donation Society (SNEDS, https://www.snedsbd.org) is a charity-based eye donation center which was established in 1977 by students at the Dhaka Medical College Hospital (DMCH). Medical students first organized themselves in different teams and later appointed counselors to collect corneas from voluntary donors who are deceased or diagnosed brain-dead. In this regard, the counselors of the SNEDS team convinced the families of brain-dead donors to give consent to donate eyes following death. Culturally, people in Bangladesh are not accustomed to donating organs after death. It is known that most posthumously donated corneas are collected by the SNEDS team from unclaimed dead bodies in hospitals (Haider 2007). Between 1984 and 2017, more than 5500 corneas from deceased donors were transplanted (Rahman and Mahmood 2017). Although a few notable Bangladeshis have donated their dead bodies, the intended use was for medical study and research purposes (Dhaka 2014). Public perception regarding body donation for medical study and research purposes is negative. The reason behind this negative attitude is cultural and religious, stemming from a lack of awareness and information about body donation, and resentment of new ideas (Chakraborty et al. 2010).

Aside from posthumous donation of corneas, transplantation of vital organs, such as the kidney, liver, heart, pancreas and other body parts or organs, from deceased donors is absent in Bangladesh. The Human Organ Transplantation Act (HOTA) officially came into effect in Bangladesh on 13th April 1999, allowing organ donation from both brain-dead and related living donors for transplantation. A fatwa, or religious approval from religious leaders, was also obtained before passing this 1999 legislation. The act was amended by the Parliament on 8th January 2018, mainly to emphasize the successful introduction of posthumous organ donation for transplantation and the extension to include the living related donor pool to the existing act. Although there is no legislature limiting it, vital organ donation from deceased donors is absent in Bangladesh, as many hold that Islamic religious principles are not compatible with the practice. As there is no clear ruling in the primary sources of Islamic jurisprudence, such as the Quran and Hadith, about organ donation 
for transplantation, it has resulted in differing opinions on the issue among Muslim scholars, religious jurists and believers (Ismail et al. 2012; Al-Khader et al. 2003; El-Shahat 1999). Many opinions are favorable, while others are in opposition (Atighetchi 2007; Aasi 2003; Ebrahim 1995). This difference in understanding among Islamic scholars and jurists creates confusion among Bangladeshis with regard to whether they themselves should donate their organs after death. Similarly, in Hinduism, as there is no single spiritual leader and no universal authority (Oliver et al. 2011), views on posthumous organ donation for transplantation differ among religious leaders and believers in Bangladesh. As organ donation involves compromising bodily integrity (Ghaly 2012; Rady, Verheijde, and Ali 2009), Bangladeshis commonly see the practice as a violation of bodily integrity and physical wholeness and, as a result, to be impermissible. On the contrary, the dead should be buried as soon as possible (Oliver et al. 2011) so as to protect their honor and maintain respect (Al-Khader, Shaheen, and Al-Jondeby 2003). Maintaining integrity of the dead body and the dying process, where a dead body is treated with the utmost care and respect, is a custom for Bangladeshis. Bangladeshis thus feel uncomfortable donating organs for transplantation after death.

The absence of transplantation of vital organs from deceased donors creates many societal problems in Bangladesh. As living relatives are the only allowable sources of organs for transplantation in Bangladesh (Rashid 2014; Siraj 2016), the huge demand for transplantable organs outstrips supply. As a result, the practice of organ selling and buying thrives in the black market (Moniruzzaman 2012). Organ buying and selling is an immoral practice (Efrat 2013; Atighetchi 2007; El-Shahat 1999; Syed 1998) and is prohibited in Bangladesh (Siraj 2016; Moniruzzaman 2012). Conversely, if transplantation of vital organs from deceased donors could be introduced in Bangladesh, it could save lives or improve the quality of life of many end-stage organ failure patients, as well as protecting poor people from being coerced into selling their organs (Siraj 2016). It is, therefore, important to undertake a thorough investigation into how to introduce a system facilitating the transplantation of vital organs from deceased donors in Bangladesh. An ethical question necessarily arises in this regard: why is there no transplantation of vital organs from deceased donors in Bangladesh? The objective of the present study is to find relevant ethical and cultural explanations. This study aims to explore the obstacles and ways forward in establishing a successful posthumous organ donation program in Bangladesh.

\section{The Dynamics of Posthumous Organ Donation, Religion and Culture}

Organ donation to save another life is generally considered, according to Atighetchi (2007), to be a humanitarian act, and with this understanding organ donation for transplantation is usually acceptable in religious and cultural terms. Conversely, organ transplantation is not morally allowed if the donor or donor's family does not give explicit consent (Güden et al. 2013; Aita 2012), despite many countries now practicing organ confiscation (Hughes 2009). Advances in medical science have expanded the scope of transplantation and offered new hope to many patients by providing effective medical therapy, saving and transforming the life of the recipient 
(Grinyó 2013; Robson et al. 2010). The major problem lies in the practice of identifying an organ donor. Living donors can donate organs to save the lives of end-stage organ failure patients, but predominantly organs come from deceased organ donors (Truog 2005). The problem of procuring organs from the deceased arises in cases of patients with families; firstly, because it is difficult to discuss organ donation in a time of grief, and, secondly, because the family needs to provide consent for organ donation to occur.

There are national differences on the issue of willingness to engage in organ donation (Abdeldayem et al. 2016; Balwani et al. 2015; Mohsin et al. 2010; Albright et al. 2005; Bennett and Savani 2004; Yeung et al. 2000). There are infrastructural, institutional, religious, cultural, and legal differences, and differences in consent systems that influence posthumous organ donation for transplantation worldwide (Abdeldayem et al. 2016; Irving et al. 2012; Newton 2011; Abadie and Gay 2006; Vathsala 2004). Lack of institutional support, such as the provision and availability of an Intensive Care Unit (ICU), and the acceptance of a legal definition of brain death as representing true death, in addition to a lack of an institutional registry system issuing donor cards, discourages potential donors from donating organs in many countries of the world (Al Sebayel and Khalaf 2004; Vathsala 2004; Cameron and Forsythe 2001). Similarly, obtaining explicit consent for organ donation from the bereaved family of a deceased donor is another critical issue that impacts the success of transplantation (Vathsala 2004). Without having explicit consent from the family of the deceased it would be impossible to remove organs even from a deceased donor who consents. Medical practice is to not obtain organs from a dead body without the consent of the family (Wilkinson 2005). Apart from legal and institutional issues, a misconception of the religious stance on organ donation, allowances for financial incentives for donors or their families, and the option of receiving organs for future potential recipients influences individual attitudes (Levy 2018; Balwani et al. 2015; Albright et al. 2005). The perception of altruism differs in different societies and cultures, in the degree to which it motivates individuals to help others in times of necessity and creates a positive attitude about organ donation influences the willingness to become an organ donor (Newton 2011; Yeung et al. 2000).

The World Health Organization (WHO) refers to two categories of posthumous organ donation; Brain Death Donation (BDD) when patients are diagnosed as braindead, and Donation after Circulatory Death (DCD) when patients die through circulatory death (Domínguez-Gil et al. 2011). The symptoms of brain death are that pressure within the skull is raised, blood flow to the brain is cut off, there is no possibility of regaining brain function and the entire brain dies (Nguyen 2016; Laureys 2005; Lovasik 2000). The organs of brain death patients are kept alive through artificial ventilation in the ICU. Artificial ventilation means that the heart continues to beat providing the possibility of healthier organs for transplantation (Iriarte et al. 2012). This is because aggressive, intensive and artificial medical support is required for brain-dead patients to facilitate successful organ recovery and transplantation (Manara and Thomas 2020; Tanim Anwar and Lee 2019). In cases of circulatory death there are catastrophic brain injuries resulting from circulatory death (Rodríguez-Arias et al. 2011; Wood et al. 2004). In these cases, life support is withdrawn, the heart ceases to beat, and body organs are damaged (Manara et al. 
2012). As such, the transplantation potential of resulting organs is reduced. Consequently, biomedical science depends more on brain-dead donations to maximize the likelihood of successful transplantation (Dixon and Malinoski 2009) and organs for donation are most commonly retrieved from brain-dead donors (Iriarte et al. 2012). Despite the concept of brain death being widely accepted and legally approved, disagreements exist and not all neurologists and scholars share the same opinion (Laureys and Fins 2008; Bagheri et al. 2003; Bardell et al. 2003; Halevy 1993).

As the determination of declaring death depends on cultural and religious perspectives, and has changed over time (Randell 2004), a wide variation in the documentation declaring brain death creates confusion among people from different cultures and religions (Busl and Greer 2009). This confusion may result from a lack of public understanding of death as a social construct, as it is defined differently by differing personal judgments (Truog et al. 2018). The social definition of death lacks the conceptual uniformity of the medical determination of brain death (Potter 2017; Lamb 1978). The concept of brain death was first introduced in 1959 as the state of deep coma, due to primary brain damage without any chance for recovery (Mollaret and Goulon 1959). In 1968, the Ad Hoc Committee of Harvard Medical School described brain death as an irreversible coma with the recognition of a new definition (Beecher 1968). In 1981, the President's Commission for the Study of Ethical Problems in Medicine and Behavioral Research redefined brain death as the complete and irreversible cessation of whole brain function (Verheijde et al. 2018; Busl and Greer 2009). While the Uniform Determination of Death Act was subsequently adopted in the United States based on these principles as legal guidelines, the Act does not provide practical guidelines (Busl and Greer 2009). As a result, medical personnel remain free to adopt accepted medical procedures, diagnostic tests and equipment as the practical guidelines for declaring brain death criteria were not set in the Act (Busl and Greer 2009). The President's Council on Bioethics in 2008 maintains the principles of the President's Commission as the cessation of whole brain function (Verheijde et al. 2018). The justification for redefining brain death varies periodically, fundamental disagreements have been raised and not been resolved (Verheijde et al. 2018). Similarly, the variation in the practice of diagnosis of brain death varies by country and region, resulting in the possibility that a patient could be considered dead in one country or region but not in another (Smith 2020). Consequently, medical personnel are often hesitant to declare someone brain-dead when the heart is still beating. A group of scholars, including Truog et al. (2020), have recently published their recommendations with regard to the formulation of the consensus about determining brain death by neurologic criteria based on the medical literature and the opinion of a large international multidisciplinary expert panel. Their statement can serve to guide medical professionals in different societies and countries in revising or developing protocols and procedures for the determination of brain death using neurological criteria that will ensure greater consistency within and between countries.

Organ donation for transplantation is a biomedical field that has witnessed a dramatic periodic change over the past decades (Rady, Verheijde, and Ali 2009; Kauffman et al. 2007). Advancements in medical science and technology have thus required Muslim scholars and jurists to periodically consult with medical 
professionals to contextualize the science behind the changes as it is pertinent with the Islamic jurisdiction (Gatrad and Sheikh 2001). Despite brain death being widely accepted as a preferred source of posthumous organ donation for transplantation (Manara and Thomas 2020), it is not to be considered as true death by fiqh, or Islamic jurisprudence, because the heart of a brain-dead patient has not stopped beating (Golmakani et al. 2005). Islamic scholars generally view death as a "physical" and "metaphysical" event which is inseparably intertwined (Golmakani et al. 2005 , p. 107). Physical death is defined when a patient's heart has stopped beating and the body becomes cold. In metaphysical death, a patient is declared dead when the soul (ruh) has departed from the body. So, the human body contains a soul as long as the heart continues to beat, as the Quran refers to death as the irreversible departure of the soul from the body (Quran 32:8-9). The interpretation of this verse is that the body is connected to the soul as long the heart continues to beat (Rady et al. 2009). Muslim scholars thus view organ donors who are declared brain-dead are in the process of dying, but are not really dead (Rady et al. 2009; Al-Mousawi et al. 1997). As a result, the opinion of Muslim scholars on the definition of brain death varies (Padela, Arozullah, and Moosa 2013). Therefore, the act of withdrawing life support from a patient whose heart is still beating is likely a harm that brings the soul from the body, equal to committing murder (Padela, Arozullah, and Moosa 2013; Golmakani et al. 2005). Muslim families thus do not want to accept brain death as actual death and resist organ donation for their relatives and loved ones as they believe their death to still be questionable.

Religion (din) is perceived to be a barrier to organ donation and transplantation. Therefore, in the formulating of law allowing posthumous organ donation for transplantation, religious interpretations are given importance. Religious leaders are engaged in the process of giving explanations on the basis of their theological knowledge and with reference to religious scripture. The government also provides religious scholars with accurate and detailed information about the concepts of brain death, and organ donation for transplantation for saving a patient's life. The majority of the people in Bangladesh are Muslims, and Islamic leaders have given a religious verdict (fatwa) in favor of organ procurement from brain-dead patients whose hearts are still beating, but who have been declared dead using neurological criteria (Section 2:3). The human body has a special honor in Islam and violating the body, either living or dead, is forbidden (Ilyas et al. 2009). It is also stated that this prohibition can be waived in the case of necessity, such as saving a human life, which is one of the basic rules in Islam (Quran, 5:32). As a result, many Muslim scholars consider posthumous organ donation for transplantation to be an expression of altruism, generosity, moral duty and responsibility, charity and cooperation (Moazam 2006; Albar 2012; Crowley-Matoka and Hamdy 2015). Conversely, Aasi (2003) mentions that some Muslim scholars do not approve of organ donation for many reasons, including loss of respect for the dead, and fear of punishment in the afterlife. In fact, biomedicine, religion and culture all embrace the idea that every patient should be offered the best available treatment regardless of the circumstances. The central point of view in Islam is preserving human life, which is precious (Moazam et al. 2014; Kamal 2008; Golmakani et al. 2005; Akrami et al. 2004). 
Although religious views have been identified broadly as a barrier to organ transplantation and an obstacle for organ donation, they may actually reflect cultural attitudes that transcend religion (Truog 2005). Modern age has seen the nature of disease become universal, i.e., it is the same everywhere, as is the medication used to treat it. So why ought biomedical practice be different (ten Have and Gordijn 2011)? It is deterministic in the sense that biomedical practice is based on science and not culture, and therefore it should be the same everywhere. But biomedical practice varies from culture to culture (Engelhardt and Rasmussen 2002) because there is a wide diversity of culture and local customs associated with healing (Rassool 2000). Islam accepts differences (Rassool 2000). Bioethicists thus emphasize that differences in the practice of biomedicine, such as the inability and unwillingness of certain populations to accept organ transplantation from deceased donors, should be explained through contextual analyses of cultural differences (Ralph et al. 2016; Wong 2010; Atighetchi 2007). The reluctance of a family to donate a deceased loved one's organ is not simply assumed to be the result of religion. The underlying barrier to organ donation is people's understanding of religion in a given place and time. Most of the negative attitudes towards organ donation for transplantation may be due to the uncertainty about the religious stance, and the fear of unknown consequences rather than religious teachings.

An argument put forward by Zhang (2020) is that biomedicine regards the body as a tangible, physical entity, while the body is conceptualized differently in different cultures (Sharifian et al. 2008). The physical body, made of further tangible structures of organs, tissues and cells (Zhang 2020) is inextricably integrated with bodily function (Nair-Collins and Miller 2017). After the last breath, the person becomes a body or an object whose organs can be obtained for transplantation by violating bodily integrity. But the importance of bodily integrity depends on cultural beliefs. The body is still a relative and loved one to the family. Dissection or mutilation of the body is commonly perceived as a violation (Moazam 2011; Daar and Khitamy 2001). It may be believed that the deceased person could still feel the pain (Nguyen 2016; Black 1987). Alternatively, it may be believed that in resurrection the deceased will have need for their organs (Abdeldayem et al. 2016; Alkhawari et al. 2005) because the human body will be resurrected on the Day of Final Judgment in order to receive either rewards or punishments (Aasi 2003; Ebrahim 1995). The religious belief is that when an organ is obtained for transplantation, the integrity and wholeness of the human body is violated (Rady et al. 2009) and families of braindead patients perceive such an action to be unacceptable (Sanal 2005). Despite the irreversible nature of the loss of brain function, medically and clinically, the patient is dead but mechanical ventilation maintains their beating heart and keeps blood flowing to their organs to keep them alive (Nair-Collins and Miller 2017; Green and Wikler 1980). Although the brainstem is non-functional, and removal of organs is legally permissible, the vital organs still function and the body remains biologically alive (Nair-Collins and Miller 2017). It is feared that brain-dead patients may feel pain when organs are removed from the body (Nguyen 2016; Nair-Collins 2010). These cultural features may act as barriers against posthumous organ donation for transplantation. 


\section{Justification of Organ Transplantation in Islamic Scriptures}

Bangladesh is a majority Muslim society with a population of nearly 165,000,000. About $90 \%$ of the Bangladeshi population is Muslim while Hindus constitute $8.5 \%$. Islam is a holistic religion that instructs the vast majority of Bangladeshi Muslims how to lead their lives and conduct their daily activities. Muslims consider Islam to be a complete code of life. Therefore, the perceptions of the Bangladeshi people in relation to organ donation for transplantation are influenced by religious teachings. The issue needs to be discussed and interpreted appropriately in the light of the Islamic scripture and its jurisprudences. Islam always values saving human life over the dead (Albar 1996, 2012; Tober 2007). Saving a human life is of great value in Islam (Golmakani et al. 2005; Mohsin et al. 2003; Kamal 2008) as the following verse of the Quran illustrates "And if anyone saved life, it would be as if he saved the life of all mankind" (5:32). Muslims consider organ donation acceptable in certain circumstances, for example, to save a human life (Syed 1998). As organ transplantation is a modern medical and technological invention, it is not literally mentioned in the Quran or the Hadith (Al-Khader et al. 2003; El-Shahat 1999; Ebrahim 1995). If the answer for a particular issue cannot directly be found in the Quran (verbatim sayings of Almighty Allah) and Hadith (sayings, actions, works and tacit assents of the Prophet Muhammad and his companions) (Syed 1998), Muslim scholars are prescribed to use secondary sources such as the Ijma or opinions on the basis of consensus (Atighetchi 2007). If the first three sources fail to provide a clear ruling on a particular issue, it is lawful to use Qiyas (analogical reasoning) and Ijtihad (exhaustive efforts) to find the divine intent (Aasi 2003). If the Qiyas/Ijtihad fails to offer a clear ruling in given circumstances, Muslims then prefer to cite subsidiary sources such as the Istihsan (preferential reasoning), Urf (customary conventions) and Maslahah (cannon for public welfare and common good) (Aasi 2003; Atighetchi 2007). Bangladeshi Muslim scholars and jurists (majority Sunni Hanafi believers) prefer to find an explanation from Maslahah.

\section{Religious Arguments Opposing Organ Transplantation}

There are several Islamic beliefs used by Muslim scholars to support the argument in opposition to organ donation for transplantation (Aasi 2003; Ebrahim 1995). Firstly, Muslim scholars cite the principles of the Quran (4:58) that human life is the divine gift and the human body including its integral organs is an $\mathrm{Al}$ Amanah, or trust that Muslims receive from Almighty, not the sole property of humans themselves. Muslims should maintain this trusteeship, men cannot donate any of their organs which are not their own (Aasi 2003). The human body should not be altered in any way. Removing organs by cutting the human body is a bodily alteration that is not allowed in Islam. By citing Quranic verse (11:22), scholars argue that Muslims should treat their body well and Muslims who are righteous 
will be rewarded with happiness in Al-Akhirah or the hereafter. Secondly, scholars cite the Quranic verses $(2: 195 ; 5: 32 ; 8: 27 ; 17: 70)$ to support their argument that removing organs for transplantations should not be allowed in Islam as the human body and human life is considered to be sacred. Scholars who oppose organ donation for transplantation also cite the following Prophetic traditions to support their argument, in that "breaking the bone of a dead person is equal to breaking it while a person is alive" (Ebrahim 1995, p. 293). They see organ donation as an act of aggression against the human body (Ebrahim 1995). Thirdly, scholars who are against organ donation also hold the view that human life and the human body should not be used as a means of leverage to gain something else. Muslim scholars, therefore, argue that "a person can never consume the flesh of another person, even if he is close to death from starvation" (Aasi 2003, p. 731). Fourthly, Muslim scholars cite Quranic verse (30:30) stating that no alteration of Almighty's creation is acceptable in Islam. They opine that Almighty will not accept those who alter His creations by cutting the human body and obtaining organs for the purpose of transplantation. Organ donation is considered to be an alteration of Almighty's creation and Muslims who alter Almighty's creation will be punished in Al-Akhirah or the afterlife.

Muslim scholars who oppose organ transplantation generally follow the literal meaning of the verses of the Quran and the Hadith (Aasi 2003). These scholars are in the minority among contemporary Muslim scholars and jurists, as there are a significant number of Muslim scholars who support such biomedical practices and they use the same scriptures (the Quran and the Hadith) to support their argument (Aasi 2003). They support organ transplantation as it is a modern invention of medical science and technology, and do not follow the literal and rigid interpretation of the scriptures (Aasi 2003). They argue that the purpose of Islamic law is to serve the betterment of human society, so the practice of organ transplantation should be endorsed legally as it provides human benefit rather than harm (Aasi 2003). They use three principles, namely the enhancement of public welfare, the common good (Maslahah); altruism (Ithar), and the acceptance that the human body and life is a sacred trust which can be used to support organ donation for transplantation (Aasi 2003).

\section{Islamic Interpretations Supporting Organ Transplantation}

Despite Islam forbidding violating the human body (Oliver et al. 2010), necessity can make prohibited things permissible in Islam (Atighetchi 2007; El-Shahat 1999; Moazam et al. 2014) if it ensures welfare and good. Organ transplantation is permissible by Muslim scholars on the basis of the principle that the pressing needs of the living outweigh the lesser benefits of the dead (FILIZ 2012). Organ transplantation, though prohibited, can be permissible in the case of necessity (Natour and Fishman 2011; Atighetchi 2007; Akrami et al. 2004; El-Shahat 1999; Al-Mousawi et al. 1997). The Quranic verse states "Say: ....whoever is forced by necessity, neither desiring it, nor transgressing its limit, thy Lord is forgiving, merciful" (6:145). Another Quranic verse (16:89), is used by Muslim scholars 
to argue that Islamic law allows forbidden things to become permissible in the case of extreme necessity. Quranic verse (2:173) can be interpreted to argue that if a person is starving or in danger, and only dubious meat or pork is available, the pork may be eaten for sustaining life (Aasi 2003). An example often cited by Muslim scholars who support and favor organ donation for transplantation is that "if a pregnant woman is dead, but there is a chance that her unborn child may still be alive, it is permissible to cut open her body to remove the child" (Aasi 2003, p. 733). If a human life is adversely affected without having an organ, donation for transplantation can be permitted (El-Shahat 1999; Aasi 2003). On the basis of that juridical principle, the pressing need for organ donation for transplantation has been considered as a necessity, which allows a traditionally prohibited action permissible, such as the violation of the body, to obtain organs for transplantation (Rady et al. 2009).

Based on an altruistic framework, activity conducted for the purpose of saving human life is permissible under Islamic law (Aasi 2003). Muslim scholars refer to the verse of the Quran (5:2) that supports human altruism; "cooperate with one another in righteousness and piety, and do not cooperate in sin and transgression. Have fear of Allah. Allah is stern in punishment." This is interpreted as that Islam encourages Muslims to be careful and cooperative in their communities in "righteousness" and "piety" and not in "sin" and "transgression" (Quran $5: 2$ ). As saving the life of a vulnerable patient is a good act, Muslim scholars affirm that such cooperation is surely a good deed (Aasi 2003). This altruistic principle would thus include human organ transplantations performed in order to save human lives. Scholars often cite the following Quranic verse in support of organ transplantation; "if anyone saved a life it would be as if he saved the life of the whole community" (Quran 5:32). The following Prophetic tradition is also often cited; "there is no disease that Allah has created, except that He also has created its treatment" (Bukhari and Muslim). Scholars view that Muslims are encouraged to find new medical treatments and apply them if successful (Albar 1996). Another principle argued by scholars who support organ transplantation is that human life is a sacred trust, and should be preserved (Aasi 2003). As the human body is on a short trusteeship from Almighty, human life and the human body should be protected and cared (Aasi 2003). Scholars often cite the following verse in support of organ donation "O believers! Do not consume one another's wealth through unlawful means; instead, do business with mutual consent; do not kill yourselves by adopting unlawful means. Indeed Allah is Merciful to you" (Quran 4:29). However, scholars and jurists in the Muslim world reached a consensus about organ donation in the International Seminar on Organ Donation and Transplantation organized by the Indonesian Council of Ulama together with the Federation of the Islamic Medical Association (FIMA) and the Indonesian Forum for Islamic Medical Studies in Jakarta on 30th July 1996. The Resolution determined that as the human body and its internal organs belong to Almighty Allah (Quran 2:195), these divine assets were created for the welfare and benefit of humankind (Quran 2:29), so men can use organs for the welfare and benefit of the community (Atighetchi 2007), meaning that organs can be used in certain circumstances when there is no alternative option (Ebrahim 1995). 


\section{Difference of Opinion Surrounding Posthumous Organ Transplantation}

The next relevant issue is defining the Islamic position regarding organ donation from the deceased. Muslims believe that the human body is composed of dust, and returns into dust following death (Quran 20:55). The human body is subsequently resurrected from dust in the same nail and vein and will be rewarded and punished in the hereafter for their deeds on the day of final Judgment. The skins and other organs will bear witness in the hereafter (Quran 41:20-22). As the human being is comprised of both the body and the soul, these two things are thus inseparable (Aasi 2003). Scholars who oppose donation from the deceased commonly argue that the soul will be resurrected with the whole body as they have hitherto, and as such, the human body should not be disfigured in any way (Aasi 2003; Ebrahim 1995; Padela et al. 2013). Conversely, scholars who support donation from the deceased unanimously agree that accepting donated organs from deceased donors is lawful in Islam as its purpose is to reduce or counteract harm (Aasi 2003; Atighetchi 2007; Ebrahim 1995) and that saving a human life takes precedence over preserving the intactness of the dead body (Chamsi-Pasha and Albar 2013; Golmakani et al. 2005).

Muslim scholars who support organ donations from the deceased argue that organs can be obtained from deceased donors when the following conditions are met: (1) it is likely that transplantation is the only effective method of treatment; (2) the expected outcome of this procedure is likely positive; (3) the consent of the donor or of their legal successors has been obtained; (4) death has been determined by Muslim physicians of good standing; and (5) the recipients have been informed about the procedure and its consequences (Ebrahim 1995). It is even lawful to obtain organs from unknown deceased donors if the relevant administrative authorities give consent (Chamsi-Pasha and Albar 2017; Albar 1996). Scholars argue that organs can only be obtained from a dying person who is free from any disease that may negatively affect the recipient's health (Aasi 2003). Organ transplantation from deceased donors has the potential to significantly extend life and significantly improve the quality of life in the majority Muslim society of Bangladesh. Further, the practice is permitted by religious rulings (fatwa) and the HOTA allows the removal of organs from brain-dead donors for transplantation. However, the reality is that aside from a few cornea transplantation surgeries (Rahman and Mahmood 2017), the transplantation of vital organs from braindead donors is still absent.

\section{Posthumous Organ Transplantation in Different Countries}

Deceased donors are considered by medical scientists as the main source of organs for transplantations in many developed countries. Posthumous donation in developed countries reaches $25-30 \%$, resulting in $90 \%$ of organs for 
transplantation coming from deceased donors (Balwani et al. 2015). For instance, a total of 18,452 transplants were performed in the United States during the period of January to June 2020, of which 15,934 was from deceased donors, and 2518 from living donors (OPTN 2020). There are two proposed reasons for this. Firstly, there is no potential harm involved for the donors. Secondly, multiple organs can be obtained from each donor that can be used to save the lives up to eight people (HRSA 2020). As organs from deceased donors still do not fulfill the huge demand for transplantable organs in developed countries, living donors are also allowed to donate organs for transplantation (Truog 2005).

Although posthumous transplantation has occurred in many majority Muslim countries such as Turkey, Saudi Arabia and Iran (Daar 1997), such practice is still in the process of development. Iran is leading example among Muslim societies, where transplantation using organs from deceased donors has been introduced successfully (Einollahi 2008). But this supply is very scarce (Larijani et al. 2004). People know that there is no religious conflict of interests for posthumous donation in Islamic jurisprudence. Conversely, the obstacles to posthumous donation are sociocultural perceptions and the strong feelings of relatives. These consist of a feeling of anxiety around rumors and accusation around the procurement of organs from their loved ones. Larijani et al. (2006) have argued that the Iranian people have faith in the miracle of Almighty and fear the inadequacy of the measures taken to save the lives of their relatives. Consequently, Iranians carry some socio-religious misconceptions around disfiguring the dead bodies of their relatives (Larijani et al. 2006). Muslims in Bangladesh also believe in rumors and accusation about disfiguring the dead body as wrong deeds and that the wrongdoer will be punished on the day of the final Judgment.

This biomedical practice is also mostly absent in the majority Muslim state of Pakistan. Posthumous corneal transplantation has been initiated in Pakistan, but these are mostly imported from abroad (Al-Shifa Trust Eye Hospital 2020). The first successful kidney transplantation from a deceased donor in Pakistan was carried out at the Sindh Institute of Urology \& Transplantation (SIUT) in 1995 with kidneys gifted by the Euro-transplant International Foundation in the Netherlands (Shams 2017). Only a limited number of kidneys have been obtained from native Pakistani deceased donors for transplantation (Shams 2017). The 2010 Human Organ Transplantation Act of Pakistan allows the deceased to donate organs for transplantation, but the practice is comparatively absent. This is likely due to the majority of Pakistanis holding socio-cultural and religious misconceptions with regard to organ donation (Moazam 2013). An important reason for not successfully introducing posthumous organ donation in Pakistan is that the general public believe that Muslims should not damage the dead body for the retrieval of organs (Hafeez 2018). Recently in 2018, the Senate Standing Committee on National Health Services passed a bill which will make it possible for people to donate their organs after their death (Junaidi 2018). Posthumous transplantation has started in neighboring India and Sri Lanka, but donation rates are still very low (Abraham et al. 2016; De Silva et al. 2017). The rate of posthumous organ donation in India is less than 1 per million population (pmp), which is low compared to that in developed countries (Kumar et al. 2019). Despite the rate of donations 
from deceased donors in India being higher than Sri Lanka, it is also negligible. For example, a total of 830 deceased donors donated almost 2400 organs in India while Sri Lanka sees around 40-50 deceased donors each year (Shroff 2018).

\section{Barriers to Posthumous Organ Donation in Bangladesh}

Medical experts and researchers have identified some of the problems preventing the initiation of vital organ transplantation from brain-dead donors in Bangladesh. Major obstacles include a lack of interest among physicians, lack of training for the transplant coordinator, who declares patients brain-dead, negative patient and public attitudes towards posthumous organ donation, a lack of ICU beds, and an incompleteness of the legislation covering the declaration of brain death (Rashid 2014). Further reasons include the lack of required infrastructure, namely facilities and resources, religious misconceptions, a lack of public motivation, the high cost of immunosuppressive drugs and a general lack of understanding around posthumous organ donation for transplantation (Rashid 2004).

Although few posthumously-donated corneas have been transplanted in Bangladesh (Rahman and Mahmood 2017), transplantation of vital organs such as the kidney, liver, heart and pancreas from brain-dead donors has not yet begun. The reasons for the successful transplantation of corneas from brain-dead donors in Bangladesh are two-fold: (1) the collection of deceased cornea for transplantation is medically straightforward compared to other vital organs such as the kidney, and corneas can be collected within $6 \mathrm{~h}$ of death; and (2) a number of donors are already registered as potential cornea donors at SNEDS, who are able to collect corneas from posthumous donors in hospital or their own home following this communication (SNEDS 2020).

Although several attempts have been made to initiate a transplantation program of vital organs from brain-dead donors in Bangladesh, this has not yet been successful. For example, in April 2002, Dr. Badrudozza Chowdhury, the former President of the People's Republic of Bangladesh, inaugurated the first kidney donation bank which was intended to collect kidneys from deceased donors; however, this bank is not currently in operation (Moniruzzaman 2010). Bangladeshi physicians and transplantation teams (for example, physicians in Bangabandhu Sheikh Mujib Medical University (BSMMU), Bangladesh Institute of Research and Rehabilitation for Diabetes, Endocrine and Metabolic Disorders (BIRDEM), Kidney Foundation Hospital (KFH), DMCH and Combined Military Hospital $(\mathrm{CMH})$, with the help of a Korean transplantation team) are ready to perform the first transplantation of vital organs from brain-dead donors, but they are waiting for donors (The Financial Express 2020). Conversely, as there is currently no registration system for donors to register, the likelihood of identifying donors for transplantation remains low. The only options available are to identify patients who are determined to be brain-dead while in hospital and whose family gives consent, or to collect organs from an unclaimed dead body. 


\section{Stipulations About Transplantations using Posthumously Donated Organs in Bangladesh}

There was no law in Bangladesh when the first kidney was transplanted in October, 1982 (Rashid 2004; Siraj 2016). The HOTA (http://bdlaws.minlaw.gov.bd/ act-details-828.html) was first passed by the parliament of Bangladesh and published in a gazette on 13th April, 1999. This law can be applied to transplantations involving the removal of organs both from brain-dead donors and living donors. It permitted the removal of organs (not only the kidney, but also the heart, liver, pancreas, bone, bone marrow, eye, skin and tissue, and any other organs or parts of the body which are transplantable (Section 2:1). A fatwa or religious approval has been sought from religious scholars in Bangladesh. They have also recognized criteria covering both living and brain-dead donors, and allowed the donation of organs for transplantation purposes. The parliament of Bangladesh revised the existing act that, adding a few stipulations to the act, and approved it on 8th January 2018. The Act came into force on 28th January.

The Act prescribes that the term brain death refers to determining that a person's brain function has completely and permanently ceased. The Act states that a human body with a beating heart can be declared brain-dead by an authorized physician and their organs can be kept functional by life support for transplantation into another human body (Section 2:3). Section 4 prescribes that organs can be removed from a person after the declaration of brain death and transplanted into a person in accordance with Section 5 of the Act. Organs can only be removed from a brain-dead donor under certain conditions: (a) if the donor has specified that their organs can be used for the purpose of donation in their lifetime (i.e., in their will); (b) if, following death and in the absence of a will as mentioned in (a), any legal successor of the donor provides written consent for donation; (c) if, 24 hours after brain death, nobody has claimed the dead body from the hospital, or clinic, the person with administrative authority can decide; (d) in the cases of eye, skin and tissue donations, if the dead body is in an organization or other place covered by the administration of the District Commissioner, then the District Commissioner can authorize the donation. Although the Act does not require explicit consent from the family in cases where the deceased has consented, the Muslim religious culture, social customs and economic realities in Bangladesh require the absence of explicit refusal by the family of the deceased, even if the donor gave consent. Without explicit consent from the bereaved family of the deceased it would be practically impossible to remove organs even from consented deceased donors.

The declaration of the brain death committee is usually included in the donor's Determination of Brain Death (DBD). The committee is principally composed of three expert physicians with the rank of Professor or Associate Professor in Medicine or Critical Care Medicine, Neurology and Anesthesiology, as these are the physicians with the ability to declare a person brain-dead (Section 5:1). Any physician or close relative thereof, who serves on the Committee for DBD, cannot surgically perform the procedure of organ transplantation. This practice is 
prohibited as the physician or their close relative may be influenced by materialistic matters related to organ transplantation due to their serving on the committee for DBD.

The Act documents the criteria for the diagnosis of brain death. The patient in a coma must undergo continuous observation for a total of 12 hours to be declared brain dead [Section 5:2(a)]. The Act stipulates that a person in a coma cannot be declared brain-dead for the purposes of organ transplantation if any of the following states apply: (i) less than 36 hours have elapsed since the person entered a coma having received cardiogenic shock treatment; (ii) the body temperature had been below $35^{\circ} \mathrm{C}$ immediately before entering coma; or (iii) if there are drug complications arising during the coma. Any metabolic or endocrine causes of coma should be corrected [Section 5:2(b)]. If the patient has abnormal breathing, ventilator breathing must be performed [Section 5:2c)]. The brainstem reflex must be entirely absent [Section 5:2(d)] and the following states must apply: (i) both pupils are dilated and fixed; (ii) there is no reflex in either eye; (iii) there is no pain sensation reflex of any type; (iv) there is no oculocephalic reflex or "doll's eyes reflex"; and (v) there is no vestibulo-ocular reflex. If these conditions are not fulfilled (Section 5:3), the Act states that brain death can be determined by (a) brain electroencephalography (EEG) for duration of 30 minutes or brain angiogram tests; and (b) the apnea test. In the case of a child, especially between the ages of 2 and 13 years, the patient should undergo EEG for 12 hours (Section 5:4). According to Section 6 of the Act, brain-dead persons under the age of 2 years or over the age of 70 years cannot donate organs for transplantation, except for the eye, skin, tissue and bone marrow [Section 6:1(a)].

This act completely prohibits the sale of organs or receipt of any kind of financial benefits in exchange for organs. It also completely bans advertisements for the purpose of selling organs (Section 9). Section 7 (b) and (c) were added into the existing act to cover the formation of National Deceased Committee and the details of transplantation methods respectively. However, there is no clause covering financial compensation for the families of brain-dead donors to mitigate, at least, the costs of ICU and ventilator use to keep organs alive for successful transplantation. Due to the lack of healthcare provision in Bangladesh (Islam 2014; Siraj 2016; Siraj et al. 2020), this reduces the likelihood of obtaining consent from the family, due to their fear of incurring these costs.

\section{Fieldwork and the Empirical Ground}

An unstructured narrative interview was carried out with four senior transplant physicians at the major organ transplant hospitals in the capital city of Dhaka, Bangladesh. The physicians interviewed worked in the BSMMU, the KFH and the Center for Kidney Diseases \& Urology Hospital (CKDUH) in Dhaka. The objective of the interviews was to investigate the current absence of posthumous vital organ donation and transplantation in Bangladesh. Two of the physicians selected for interview held leadership roles at the KFH and the CKDUH, and other two physicians served as senior Nephrologists at the BSMMU. Their views were important to explore 
the barriers to organ transplantation, as well as how to facilitate the introduction of posthumous vital organ donation for transplantation. These four candidates were selected for interview because they regularly visited chronic kidney failure patients in hospital, and they each had more than two decades' experience in the field. The chosen physicians were highly esteemed in the Bangladeshi medical community, and consequently, patients are very open with them in relation to their health condition. Views and opinions were also collected from three patients and their relatives, who attended post-operative care clinics at the outpatient department of CKDUH, and three members of the public. These interviews were conducted to investigate the obstacles to posthumous organ donation for transplantation, and potential ways of overcoming them. One final year medical student at DMCH was interviewed who was responsible for managing SNEDS activities to collect corneas from brain-dead patients at DMCH. The student explained how they explain the situation to the families of patients who are determined to be brain-dead both in the hospital and in the home setting. Two counselors who work at SNEDS were also interviewed to explore how they obtain consent from families for the retrieval of eyes from braindead patients, both at hospital and in the home. Finally, a member of staff from the Department of Anatomy at DMCH was interviewed to explore the barriers preventing the donation of a dead body for medical study and research.

All interview appointments were pre-arranged. Each interviewee was fully informed about the objectives of the study. Verbal permission was obtained before starting each interview, as many Bangladeshi people are hesitant to sign a written consent form. Most participants were unwilling to have their interview recorded; so taking notes was the only available option for content analysis. All data were anonymized at source. A multidisciplinary qualitative data analysis technique was used for exploring the socio-cultural and religious themes regarding the practice of posthumous organ donation for transplantation in Bangladesh. Fieldwork was conducted in two separate periods in 2018 in 2020. The 2018 fieldwork period occurred after the HOTA of 1999 was revised. The 2020 fieldwork period was conducted to expand the understanding around posthumous organ donation for transplantation in Bangladesh.

\section{Obstacles to Organ Retrieval and Transplantation in Bangladesh}

People in the West are often more willing to become organ donors after death. Governments in the West run a variety of programs motivating people to become organ donors. Thus, people are made aware of the benefits of organ donation for transplantation, become enthusiastic to register as donors and carry donor registration cards. They are aware about organ donation, and as such, the rate of transplantation from posthumous organ donation in the West is higher than that from living donors. The number of deceased transplantations in South Asian countries is negligible in general, and in Muslim societies is near zero. People in the South Asian countries are guided by religion, and many people have religious misconceptions and cultural beliefs around organ donation (Shroff 2018). People believe that organ donation 
can have a negative impact in the afterlife, and are reluctant to agree to posthumous donation.

During one of the fieldwork interviews, a transplant physician was asked about obstacles that hinder posthumous organ donation in Bangladesh. The physician responded that physicians are unwilling to declare brain death for patients, resulting in a lack of unavailability of vital organs for transplantations. Physicians view the 1999 act in relation to declaring brain death as unfavourable for physicians, as the stipulations regarding posthumous donation were not seen as being comprehensively defined. Physicians are thus not in agreement in declaring brain death. A transplant physician stated "it was vague about declaring brain death of donors in the 1999 act". Physicians are not in favour of declaring brain death for a patient because they assume that people may file a case against them if they do so. The physician continued: "We could not proceed as ICU specialists are suspicious of physicians declaring brain death, so they cannot take the initiative. When a patient who is declared brain-dead by the medical team has their organs obtained for transplantation; what will happen if their family files a case assuming that brain death was only declared in order to retrieve organs? Who would declare brain death for a patient when there is a fear of imprisonment? Who would take the risk of losing their professional registration?" Transplantation depends on the condition of certainty around declaring brain death of a patient, as the new act endorses. Another physician gave a different viewpoint, in that "We can start obtaining organs from brain-dead patients and transplanting them into other human bodies. But who would want to have their licence revoked if the family of such a patient claims that we have sold the organs to the recipient? As there is currently no waiting list for potential organ recipients, the bereaved families may pose such a question as many distrust the healthcare systems." Transplant physicians said that it was this fear that discouraged the medical board and transplant coordinator not to declare brain death for a patient. These differing expert opinions and inconsistency in procedures around declaring brain death discourages Bangladeshi physicians obtaining organs from deceased donors for transplantation. Now that the government of Bangladesh has recently revised the existing act, and the stipulations in relation to posthumous donation are now welldefined, physicians are more optimistic about the future of transplantation. The difference between the stipulations in the 1999 and 2018 acts regarding the declaration of brain death are visible. The apnea test is now explicitly stipulated to be used during diagnosis, which has been viewed as positive by specialists. As such, transplant teams are empowered in relation to declaring brain death donors. It is hoped that transplantation of vital organs from brain-dead patients will commence very soon in Bangladesh. A number of foreign medical experts have also been invited to promote this medical initiative, with the government arranging a number of training programs and seminars for physicians and transplant coordinators at the forefront of transplantation procedures.

There is still a problem regarding lack of motivational training for transplant coordinators in Bangladesh. The medical team comprises three physicians who declare brain death for a patient. If the committee makes any error, or if one of the team is not in agreement, then they have to wait for over 6 hours to confirm brain death. Transplantation coordinators must be motivated to encourage the bereaved 
families to give consent. The act prescribes that obtaining organs is legal from a brain-dead donor who gives consent. But it is a cultural norm to seek consents from the donor's legal successors. A physician gave the following view: "We do not have potential posthumous donors whose vital organs, for example kidney, can be obtained for transplantation. After confirming brain death of a patient, we have to approach the patient's family for consent in obtaining organs from the dead body of their relative for transplantation. If we do it properly, a number of vital organs from a brain-dead patient can be obtained for transplantations. The fact is that success depends on the transplant coordinator. Everything depends on how the transplant councillor deals with the bereaved family when family members are grieving after hearing of the death of the patient". More training is also needed for personnel who conduct transplantation procedures, as there is a lack of training available. Limited training has been available since 2014, and a few physicians have completed it. Some such organized training programs are conducted in collaboration with medical experts in foreign countries, where nurses, junior physicians, and social workers can participate (Rashid 2018a, b).

\section{Socio-Cultural Obstacles to Posthumous Transplantation of Vital Organs in Bangladesh}

A transplant physician was asked about the obstacles that hinder the posthumous donation and transplantation of vital organs in Bangladesh. He explained that transplantation of vital organs from brain-dead patients has not started in Bangladesh because people have misconceptions about posthumous organ donation. Physicians reported that people fear donating their organs after death as they fear the consequences of cutting into the dead body for organ retrieval. As such, people are more in agreement with live donation for transplantation. Interviewees expressed that Bangladeshis do not want to donate their organs after death as there is public anxiety and fear of rumours about donating organs after death. Disfiguring the dead body to retrieve organs is seen as wrong, and that Almighty will not give mercy if they allow a physician to cut and disfigure their body. It is a common cultural belief in Bangladesh that people will be punished in the afterlife if they do a wrong thing with their body, as it is not legal in Islam. Physicians stated that Bangladeshis hold many misconceptions about posthumous organ donation. Bangladeshis, like Muslims in other South Asian countries, do not clearly know the Islamic religious teaching with regard to solid organ donation in general, and posthumous organ donation for transplantation in particular (Shroff 2018).

This lack of public awareness is commonly cited as the reason for not introducing posthumous donation of vital organs from brain-dead patients in Bangladesh. In answer to the question "Can a brain-dead donor donate organs to another person?" One family member of a patient at the outpatient department in CKDUH explained "We are not aware of posthumous donation. This is the first I have heard about the issue in my lifetime". People who live in rural Bangladesh do not know about posthumous organ donation for transplantation. 
People in Bangladesh believe in family bonds, and because of the strength of those bonds, they worry about donating their organs after death. Bangladeshis assume that disfiguring the body for the purpose of transplantations will result in severe pain and suffering that they cannot tolerate. One interviewee expressed that "If they see or hear that the body of their relatives is cut for organs, it is like the feeling of cutting their own body, and is intolerable for them". A transplant physician stated: "The challenge is that socio-cultural issues prevent the introduction of vital organ donation for transplantation. I have had conversations with my patients where they tell me that they cannot tolerate the idea that the body of their relative will be cut in order to obtain organs for transplantation". It is not that such family feelings do not exist in the West or in developed societies. In fact, family feelings cannot be isolated from the totality of society. Culture is a combination of beliefs, traditions, rituals, and practices that unite family members. It is also changeable in the context of social change. A transplant physician commented on this issue: "Family feelings and cultural traditions may influence people on the matter of donating organs after their death. I can give you an example. The Japanese are educated and also developed, but the rate of posthumous donation for transplantation is very low. The reason being that they obey their culture. It is their cultural norm that they have very strong family ties which do not permit the cutting of a dead body to retrieve organs. Conversely, Americans and Spanish cultures are much more positive about donating organs after death, as enjoy the freedom to do so. Although most Muslim countries like Saudi Arabia are agreement about posthumous organ donation for transplantation, Muslims in South Asian countries are unwilling". Muslims in South Asia, especially in Bangladesh, have negative attitudes around posthumous organ donation, despite South Asian Muslim jurists using the same Islamic sources and methodologies of argument (Moazam 2011). Bangladeshis fear that in cutting the dead body of a relative they are disfiguring the body, which is a wrongdoing, and wrongdoers will be punished in the afterlife (Quran 14:23, 43).

Vital organ transplantations have not yet occurred in Bangladesh, but transplantation of non-vital or redundant organs such as the cornea taken from brain-dead donors has been in practice since 1984. SNEDS counselors go to hospitals and homes to counsel the bereaved families with the understanding that donation is a good act and the patient will be rewarded happiness in return in the afterlife. The counselor also explains there is no religious barrier in donating corneas. A number of corneas thus have been collected, preserved and transplanted. A counselor commented on the basis of long experience in this field: "It is not an easy process. People whose patients die or are declared brain-dead will not easily allow you to obtain corneas from their relative's dead body. Many families even have religious misconceptions. They often think that if they allow the physicians to obtaining corneas, they will be punished for their wrong deeds. Many families get worried and react to our suggestion". Another counselor said: "We have to convince them by giving religious explanations. Middle class educated families mostly agree to donate corneas. Few families of consented organ donors contact us for cornea collection. But even in these cases, some families agree but the majority of the families refuse due to the fear of harming the dead body". 
A general observation is that Bangladeshis also fear donating their body for medical study and research purposes, even though a few notable Bangladeshis have done so. Conflicts arise when such the moment comes, and family members refuse to donate the body of their relative. A professional who teaches Anatomy at DMCH outlined his experiences: "I can give you an example. I saw conflicts among the family members of a notable Bangladeshi on the issue of whether his body would be donated for medical study and research purposes at the hospital. When he died, family members disagreed about whether it would be donated or brought back home for burial. It took a long time to reach a final decision and the body was kept in the hospital until the decision was made". It is unusual that people from lower socio-economic groups donate their body for medical study or research purposes. Usually in Bangladesh only a few educated and progressive people voluntarily decide to donate their bodies. A medical professional commented: "It is usual from my experience, as people generally do not want to see the body of their relative taken away for medical study and research purposes. People are accustomed to seeing the dead body taken for burial. They consider it to be their moral duty. If a dead body is buried, relatives can show respect to them by visiting the graveyard. It is difficult for people to forego performing death rituals". Religious misconceptions and cultural beliefs hinder posthumous donation of vital organs for transplantation and also body donation for medical study and research.

\section{Facing the Challenges Ahead}

Posthumous organ donation has the potential to save a number of human lives (Raho et al. 2019). The formation of a National Deceased Committee to oversee the organ transplantation program is a good initiative that the government has endorsed in the Act. Committee members have been collectively working to initiate posthumous donation of vital organs. One physician interviewed explained that the National Deceased Committee has selected ICUs in different medical hospitals to initiate transplantation of vital organs from brain-dead donors. If these measures have positive outcomes, the effort will be increased. We have to motivate Bangladeshis to donate their organs after death. Physicians also acknowledge that posthumous organ donation is a new concept for Bangladeshis; as such they are not mentally ready for donating organs after their death. A national public awareness program is needed to motivate people to become organ donors. A physician added: "Physicians are now ready to perform transplantation of vital organs from deceased donors. Deceased donation has many advantages as a single brain-dead donor can save the lives of many patients. The challenge we face is that there are no registered donors. If potential donors are identified, transplant coordinators in authorized hospitals may consult with the families to seek consent while the patients are in the final stage in the ICUs".

Respondents suggested that counseling of patients' families and training of transplantation teams should emphasize vital organ donation. According to the Act [Section: 7(4)], a transplant coordinator is recruited in each hospital where organ transplantations are being performed. The role of a transplant coordinator is to motivate 
family members who are suffering from grief to enlist as donors. Although the Act does not require explicit consent from the family in cases where the deceased has consented, practically, factors such as the Muslim religious culture, cultural beliefs, and societal ethos in Bangladesh require the absence of explicit refusal by the family of the deceased. Counselors and medical students acknowledge the need to receive consent from the bereaved family of a consented donor when corneas are obtained for transplantation. An experienced and well-trained approach is required when seeking consent from bereaved family members. Thus, transplant coordinators should be trained to receive consent from bereaved family members. With the help of foreign medical experts, a number of training courses and seminars are organized every year by the SOT, Bangladesh to train nephrologists, urologists, cardiologists, orthopedics, hematologists, ICU specialists and transplant coordinators in Bangladesh. More training programs are needed for transplant coordinators, particularly around how to approach and receive consents from donors' families.

Besides institutional training and seminars, a charitable organization should be formed, to offer proper training for transplant coordinators, similar to what the Multi Organ Harvesting and Networking (MOHAN, https://www.mohanfoundation.org) foundation is doing in the Tamil Nadu State in India (Abraham et al. 2016). Further charity efforts should be encouraged. SNEDS is working towards the posthumous collection of eyes from brain-dead donors in Bangladesh. Similarly voluntary grief counselors may be recruited to consult with families of brain-dead donors to promote vital organ donation. The MOHAN foundation in India primarily provides grief counselors training at Madras Medical College on counseling potential donors' families. As a result, the organ donation rate in Madras is higher than that of other areas in India (Balwani et al. 2015). Similarly, SNEDS is currently highly successful in the collection of posthumous corneas in Bangladesh, whereby the counsellor collects posthumous cornea donations while consulting with the bereaved relatives in ICUs, hospitals and at home. A SNEDS counsellor explained: "It is good for us that we can do something for the blind people. Our team usually goes to hospital as well as the home and tries to convince the family members of a patient who has just been declared brain-dead that donating a cornea may turn on the light for a blind person. We also try to convince them that donating eyes is a good act and the donor will always be in the prayers of the person who receives the donation".

A transplant physician suggested a comprehensive public campaign, especially in rural areas, as "people are unaware about donating organs for transplantation. As most people still live in rural areas of Bangladesh, such rural people need to be aware of organ donation for transplantation. The government may introduce a campaign strategy to make the public aware. I believe that middle class educated families are positive and they will donate organs if we can motivate them positively about deceased organ donation for transplantations. If we can motivate people we can find potential brain-dead donors for transplantation, a number of end-stage vital organ failure patients' lives can be saved". If vital organs, for example the kidney, are made available from brain-dead donors for transplantation, the black market sale of organs from people in poverty will no longer exist, and poor people will, therefore, no longer be forced to sell their organs for transplantation (Siraj 2016; Moniruzzaman 2012). 
A large number of people die every day in road traffic accidents in Bangladesh. Most of these people are diagnosed as brain-dead in public and private hospitals. Organs can be obtained from these bodies for transplantation. A total of 56,000 people have died in the 84,000 road traffic accidents that have occurred over the past 21 years in Bangladesh (Alam and Khurshid 2018). In recent years, an average of between 6000 and 8000 people died yearly in road accidents in Bangladesh (The Daily Star 2020), and 70\% of them are determined as having undergone brain death. As such, the country annually has approximately 4000 to 5500 potential organ donors. These brain-dead donors could save the lives of many end-stage organ failure patients, including 5000 kidney failure patients annually (Rahman and Mahmood 2017). In addition, vital organs can be used for transplantation if the Act allows the administrative authority to give permission for procuring organs from unknown persons who are declared brain-dead in hospitals, as the SNEDS team is currently doing for corneas (Haider 2007).

A national online donor registry can be established, although the law prescribes each organ transplantation hospital to document the information of the donor and the recipient (Section-8). An online data registry may make it easier to find potential brain-dead donors. The government of Bangladesh may establish an online database system like the National Organ and Tissue Transplant Organization (NOTTO, https ://notto.gov.in/Admin/Login.aspx) that was created under the Directorate General of Health Services, Ministry of Health and Family Welfare, Government of India, to oversee the coordination and networking activities for procuring and distributing organs and tissues, and the registry of human organs and tissues for the purpose of transplantation in Bangladesh. The government must allocate the required resources for the promotion of organ transplantation, especially in the formation of a posthumous organ donation for transplantation program. The government of Bangladesh, together with a charity fund, ring-fences a small amount of money at BSMMU but this is negligible. The government should allocate substantial finances to provide care for people who are in need. Related expenses such as the cost of ICU support and ventilator use should be provided to the brain-dead donor free of charge, while they are kept alive so that their organs can be preserved. These charges would usually be incurred by the bereaved families as there is almost no comprehensive healthcare coverage for the vast majority of people in Bangladesh. Families will not give consent for organ donation if they have to bear the expenses of ICU and related costs. These costs should therefore be subsidized or funded by the government or charities.

\section{Concluding Remark}

Although Bangladesh has made arrangements to start transplantation of vital organs from brain-dead donors, the country has to face many challenges to make the program successful in order to save the lives of many end-stage organ failure patients. Otherwise, only introducing a posthumous vital organ transplantation program may not ensure the desired healthcare outcomes for the country. Successful implementation of the medical initiative requires public awareness, training of 
transplant physicians and coordinators, recruiting counselors for seeking consent from bereaved families of potential donors, allocating required resources for transplantation care, and offering to cover the expenses incurred in supporting donors' families. The obstacles that hinder posthumous vital organ donation for transplantation in Bangladesh include socio-cultural and religious perceptions, which need to be addressed for the sake of saving the lives of end-stage organ failure patients.

Acknowledgements This study would not have been possible without the cordial support of the interviewees, who not only participated, but also disclosed their views about obstacles that hinder the formation of posthumous organ donation and transplantation program in Bangladesh, and potential ways of overcoming these obstacles. Thanks also go to Professor Ruiping Fan whose guidance helped in the initial design of this research. I am grateful to Professor Naseem Akhter Hussain for her insightful and beneficial comments on the manuscript. I am also thankful to Dr. Rebecca Susan Dewey, University of Nottingham, for providing me with meticulous editing work on the manuscript. This study was partially supported by the University Grants Commission (UGC) of Bangladesh research activities fund in Jahangirnagar University.

\section{Compliance with Ethical Standards}

Ethical Approval Approval was obtained from CKDUH for interviewing patients and their relatives. As the study did not involve any direct contact with patients at BSMMU, KFH or DMCH, ethical approval from the institutional ethics committees of these hospitals was not required. All procedures were conducted in accordance with the ethical standards of the institution and the national research ethics committee.

\section{References}

Aasi, G.-H. (2003). Islamic legal and ethical views on organ transplantation and donation. Zygon®, 38(3), $725-734$.

Abadie, A., \& Gay, S. (2006). The impact of presumed consent legislation on cadaveric organ donation: A cross-country study. Journal of Health Economics, 25(4), 599-620.

Abdeldayem, H., El-Kased, A. F., Elshaarawy, A., Hammad, E. S., Al-Haddad, O., Sobhi, G., et al. (2016). Religious concepts in organ transplantation. In H. Abdeldayem, A. El-Kased, \& E. ElShaarawy (Eds.), Frontiers in transplantology (pp. 1-22). London: IntechOpen.

Abraham, G., Vijayan, M., Gopalakrishnan, N., Shroff, S., Amalorpavanathan, J., Yuvaraj, A., et al. (2016). State of deceased donor transplantation in India: A model for developing countries around the world. World Journal of Transplantation, 6(2), 331-335.

Aita K. (2012) The family-oriented priority organ donation clause in Japan - fair or unfair ?" In Proceedings of the 2012 Uehiro-Carnegie-Oxford ethics conference, pp. 1-8

Akrami, S. M., Osati, Z., Zahedi, F., \& Raza, M. (2004). Brain death: Recent ethical and religious considerations in Iran. Transplantation Proceedings, 36(10), 2883-2887.

Al-Khader, A. A., Shaheen, F. A., \& Al-Jondeby, M. S. (2003). Important social factors that affect organ transplantation in Islamic Countries. Experimental and Clinical Transplantation, 1(2), 96-101.

Al-Mousawi, M., Hamed, T., \& Al-Matouk, H. (1997). Views of Muslim scholars on organ donation and brain death. Transplantation Proceedings, 29(8A), 3217.

Al-Shifa Trust Eye Hospital. (2020). Eye/cornea donations. Al-Shifa Trust Eye Hospital. Retrieved December 10, 2020 from https://www.alshifaeye.org/donation.php?p=cornea-donations.

Alam, A. B., \& Khurshid, M. (2018). Road traffic accidents in Bangladesh. Journal of Bangladesh College of Physicians and Surgeons, 36(4), 137-138.

Albar, M. A. (1996). Islamic ethics of organ transplantation and brain death. Saudi Journal of Kidney Diseases and Transplantation, 7(2), 109-114.

Albar, M. (2012). Organ transplantation: A Sunni islamic perspective. Saudi Journal of Kidney Diseases and Transplantation, 23(4), 817-822. 
Albright, C. L., Glanz, K., Wong, L., Dela Cruz, M. R., Abe, L., et al. (2005). Knowledge and attitudes about deceased donor organ donation in filipinos: A qualitative assessment. Transplantation Proceedings, 37(10), 4153-4158.

Ali, M. (2012). Organ transplantation in Bangladesh-Challenges and opportunities. Ibrahim Medical College Journal, 6(1), i-ii.

Alkhawari, F. S., Stimson, G. V., \& Warrens, A. N. (2005). Attitudes toward transplantation in U.K. Muslim Indo-Asians in West London. American Journal of Transplantation, 5(6), 1326-1331.

Asian Development Bank. (2020). Poverty data: Bangladesh. Bangladesh and ADB. Retrieved May 13, 2020 from https://www.adb.org/countries/bangladesh/poverty.

Atighetchi, D. (2007). Islamic bioethics: Problems and perspectives. Dordrecht: Springer.

Bagheri, A., Tanaka, T., Takahashi, H., \& Shoji, S. I. (2003). Brain death and organ transplantation: Knowledge, attitudes, and practice among Japanese students. Eubios Journal of Asian and International Bioethics: EJAIB, 13(1), 3-5.

Balwani, M. R., Gumber, M. R., Shah, P. R., Kute, V. B., Patel, H. V., Engineer, D. P., et al. (2015). Attitude and awareness towards organ donation in western India. Renal Failure, 37(4), 582-588.

Bardell, T., Hunter, D. J. W., Kent, W. D. T., \& Jain, M. K. (2003). Do medical students have the knowledge needed to maximize organ donation rates? Canadian Journal of Surgery, 46(6), 453-457.

bdnews24.com. (2017). Bangladesh performs 25th bone marrow transplant in the first-ever centre. Bdnews24.Com., February 13, 2017. Retrieved July 26, 2020, from https://bdnews24.com/healt h/2017/02/13/bangladesh-performs-25th-bone-marrow-transplant-in-the-first-ever-centre.

Beecher, H. K. (1968). A definition of irreversible coma. JAMA, 205(6), 337.

Bennett, R., \& Savani, S. (2004). Factors influencing the willingness to donate body parts for transplantation. Journal of Health \& Social Policy, 18(3), 61-85.

Black, J. (1987). Broaden your mind about death and bereavement in certain ethnic groups in Britain. British Medical Journal (Clinical Research Ed.), 295, 536-539.

Busl, K. M., \& Greer, D. M. (2009). Pitfalls in the diagnosis of brain death. Neurocritical Care, 11(2), 276-287.

Cameron, S., \& Forsythe, J. (2001). How can we improve organ donation rates? Research into the identification of factors which may influence the variation. Nefrología, 21(5), 68-77.

Chakraborty, S. K., Khan, H., Islam, S., \& Ali Yousuf, B. M. (2010). Body donation and its significance in anatomy learning in Bangladesh: A review. Bangladesh Journal of Anatomy, 8(2), 85-88.

Chamsi-Pasha, H., \& Albar, M. A. (2013). Western and islamic bioethics: How close is the gap? Avicenna Journal of Medicine, 3(1), 8-14.

Chamsi-Pasha, H., \& Albar, M. A. (2017). Do not resuscitate, brain death, and organ transplantation: Islamic perspective. Avicenna Journal of Medicine, 7(2), 35-45.

Crowley-Matoka, M., \& Hamdy, S. F. (2016). Gendering the gift of life: Family politics and kidney donation in Egypt and Mexico. Medical Anthropology, 35(1), 31-44.

Daar, A. S. (1997). An emerging transplant force-developing countries: Middle East and the Indian subcontinent. Transplantation Proceedings, 29(1-2), 1577-1579.

Daar, A. S., \& Khitamy, B. A. (2001). Bioethics for clinicians: 21. Islamic bioethics. JAMC, 164(1), 60-63.

De Silva, E. H., Godakandage, M. H., Peries, W. A., Dilrukshi, L. P., Gunasekera, T. D., Fernando, A. R., et al. (2017). Deceased donor organ donation in a developing country; an early experience in a tertiary care center in Sri Lanka. Transplantation. https://doi.org/10.1097/01.tp.0000525057.34891 .00 .

Dhaka, T. (2014). 22 people donate bodies, eyes. Dhaka Tribune, December 14, 2014. Retrieved September 16, 2020, from https://www.dhakatribune.com/uncategorized/2014/12/14/22-people-donat e-bodies-eyes.

Dixon, T. D., \& Malinoski, D. J. (2009). Devastating brain injuries: Assessment and management part I: Overview of brain death. The Western Journal of Emergency Medicine, 10(1), 11-17.

Domínguez-Gil, B., Delmonico, F. L., Shaheen, F. A. M., Matesanz, R., O’Connor, K., Minina, M., et al. (2011). The critical pathway for deceased donation: Reportable uniformity in the approach to deceased donation. Transplant International, 24(4), 373-378.

Ebrahim, A. F. M. (1995). Organ transplantation: Contemporary Sunni Muslim legal and ethical perspectives. Bioethics, 9(3/4), 291-302.

Efrat, A. (2013). The politics of combating the organ trade: Lessons from the Israeli and Pakistani experience. American Journal of Transplantation 13(7), 1650-1654. 
Einollahi, B. (2008). Cadaveric kidney transplantation in Iran: Behind the Middle Eastern countries? Iranian Journal of Kidney Diseases, 2(2), 55-56.

El-Shahat, Y. I. M. (1999). Islamic viewpoint of organ transplantation. Transplantation Proceedings, 31(8), 3271-3274.

Engelhardt, H. T., \& Rasmussen, L. M. (2002). Bioethics in the plural: An introduction to taking global moral diversity seriously. In H. T. Engelhardt \& L. M. Rasmusse (Eds.), Bioethics and moral content: National traditions of health care morality (pp. 1-14). Philosophy and Medicine, vol. 74. Springer, Dordrecht: Kluwer Academic Publishers.

FILIZ, S. (2012). The place of bioethics principles in islamic ethics. In B. Arda \& V. Rispler-Chaim (Eds.), Islam and bioethics (pp. 12-37). Ankara Üniversitesi.: Ankara.

Gatrad, A. R., \& Sheikh, A. (2001). Medical ethics and islam: Principles and practice. Archives of Disease in Childhood, 84(1), 72-75.

Ghaly, M. (2012). Religio-ethical discussions on organ donation among muslims in Europe: An example of transnational Islamic bioethics. Medicine, Health Care and Philosophy, 15(2), 207-220.

GoB. (1972). The constitution of the People's Republic of Bangladesh. Dhaka: Legislative and Parliamentary Affiars Division.

GoB. (1975). The blind relief (donation of eye) act, 1975. Retrieved July 26, 2020, from http://bdlaw s.minlaw.gov.bd/act-details-493.html.

GoB. (2018). Health Bulletin 2017. Ministry of Health and Family Welfare, Government of the People's Republic of Bangladesh. Retrieved September 2, 2020, from https://dghs.gov.bd/index.php/ en/home/4364-health-bulletin-2017.

Golmakani, M. M., Niknam, M. H., \& Hedayat, K. M. (2005). Transplantation ethics from the islamic point of view. Medical Science Monitor: International Medical Journal of Experimental and Clinical Research, 11(4), RA105-109.

Grinyó, J. M. (2013). Why is organ transplantation clinically important? Cold Spring Harbor Perspectives in Medicine, 3(6), a014985-a014985.

Güden, E., Çetinkaya, F., \& Naçar, M. (2013). Attitudes and behaviors regarding organ donation: A study on officials of religion in Turkey. Journal of Religion and Health, 52(2), 439-449.

Hafeez, M. (2018). Deceased organ donation in pakistan-A haunted will or an under-researched topic? JPMA The Journal of the Pakistan Medical Association, 68(12), 1852-1853.

Haider, S. (2007). The quest for corneas. The Daily Star Weekend Magazine, May 25, 2007. Vol. 6, Issue 20. Retrieved July 07, 2020, from http://archive.thedailystar.net/magazine/2007/05/04/cover.htm.

Halevy, A. (1993). Brain death: Reconciling definitions, criteria, and tests. Annals of Internal Medicine, $119(6), 519$.

HRSA. (2020). What can be donated. U.S. Government information on organ donation and transplantation. Retrieved October 8, 2020 from https://www.organdonor.gov/about/what.html\#expandcoll apse.

Hughes, P. M. (2009). Presumed consent: State organ confiscation or mandated charity? HEC Forum, 21(1), 1-26.

Ilyas, M., Alam, M., \& Ahmad, H. (2009). The Islamic perspective of organ donation in Pakistan. Saudi Journal of Kidney Diseases and Transplantation, 20(1), 154-156.

Iriarte, J., Palma, J. A., Kufoy, E., \& de Miguel, M. J. (2012). Brain death: Is it an appropriate term? Neurología (English Edition), 27(1), 16-21.

Irving, M. J., Tong, A., Jan, S., Cass, A., Rose, J., Chadban, S., et al. (2012). Factors that influence the decision to be an organ donor: A systematic review of the qualitative literature. Nephrology Dialysis Transplantation, 27(6), 2526-2533.

Islam, A. (2014). Health system in Bangladesh: Challenges and opportunities. American Journal of Health Research, 2(6), 366-374.

Ismail, S. Y., Massey, E. K., Luchtenburg, A. E., Claassens, L., Zuidema, W. C., Busschbach, J. J. V., \& Weimar, W. (2012). Religious attitudes towards living kidney donation among dutch renal patients. Medicine, Health Care and Philosophy, 15(2), 221-227.

Junaidi, I. (2018). Senate body passes bill allowing organ donation. DAWN, November 29, 2018. Retrieved July 07, 2020, from https://www.dawn.com/news/1448277.

Kamal, M. M. (2008). Ethical issues of organ transplantation in Islam. TAJ: Journal of Teachers Association, 21(1), 97-103.

Kauffman, H. M., Rosendale, J. D., Taranto, S. E., McBride, M. A., \& Marks, W. H. (2007). Non-heartbeating donors (then) and donation after cardiac death (now). Transplantation Reviews, 21(4), 237-248. 
Kumar, P., Shroff, S., Navin, S., Sahi, M. K., Jairam, J., Mathur, S. K., et al. (2019). Deceased organ donation of foreign nationals in India. Indian Journal of Transplantation, 13(4), 277.

Lamb, D. (1978). Diagnosing death. Philosophy \& Public Affairs, 7(2), 144-153.

Larijani, B., Zahedi, F., \& Taheri, E. (2004). Ethical and legal aspects of organ transplantation in Iran. Transplantation Proceedings, 36(5), 1241-1244.

Larijani, B., Zahedi, F., \& Taheri, E. (2006). Deceased and living organ donation in Iran. American Journal of Transplantation, 6(6), 1493.

Laureys, S. (2005). Death, unconsciousness and the brain. Nature Reviews Neuroscience, 6(11), 899-909.

Laureys, S., \& Fins, J. J. (2008). Are we equal in death?: Avoiding diagnostic error in brain death. Neurology, 70(4), e14-15.

Levy, M. (2018). State incentives to promote organ donation: Honoring the principles of reciprocity and solidarity inherent in the gift relationship. Journal of Law and the Biosciences, 5(2), 398-435.

Lovasik, D. (2000). Brain death and organ donation. Critical Care Nursing Clinics of North America, 12(4), 531-538.

Manara, A. R., \& Thomas, I. (2020). Current status of organ donation after brain death in the UK. Anaesthesis, 75(9), 1205-1214.

Manara, A. R., Murphy, P. G., \& O’Callaghan, G. (2012). Donation after circulatory death. British Journal of Anaesthesia, 108(S1), i108-i121.

Green, M. B., \& Wikler, D. (1980). Brain death and personal identity. Philosophy \& Public Affairs, 9(2), $105-133$.

Moazam, F. (2006). Bioethics \& organ transplantation in a Muslim society: A study in culture, ethnography and religion. Indianapolis: Indiana University Press.

Moazam, F. (2011). Sharia law and organ transplantation: Through the lens of Muslim jurists. Asian Bioethics Review, 3(4), 316-332.

Moazam, F. (2013). Pakistan and kidney trade: Battles won, battles to come. Medicine, Health Care and Philosophy, 16(4), 925-928.

Moazam, F., Jafarey, A. M., \& Shirazi, B. (2014). To donate a kidney: Public perspectives from Pakistan. Bioethics, 28(2), 76-83.

Mohsin, N., Marhuby, H., Maimani, Y., Aghanishankar, P., Al-Hassani, M., \& Daar, A. S. (2003). Living kidney donation for the mentally impaired. A case report. Transplantation Proceedings, 35(7), 2571-2572.

Mohsin, N., Militsala, E., Budruddin, M., Al-Khawaldi, H., Al-Dhuhli, Y., Al-Rahbi, Y., \& Al-Lawati, J. (2010). Attitude of the omani population toward organ transplantation. Transplantation Proceedings, 42(10), 4305-4308.

Mollaret, P., \& Goulon, M. (1959). The depassed coma (preliminary memoir). Revue Neurologique, 101, 3-15.

Moniruzzaman, Md. (2010). 'Living cadavers' in bangladesh: Ethics of human organ bazar. Toronto: University of Toronto.

Moniruzzaman, M. (2012). 'Living cadavers' in Bangladesh: Bioviolence in the human organ bazaar. Medical Anthropology Quarterly, 26(1), 69-91.

Nair-Collins, M. (2010). Death, brain death, and the limits of science: Why the whole-brain concept of death is a flawed public policy. The Journal of Law, Medicine \& Ethics, 38(3), 667-683.

Nair-Collins, M., \& Miller, F. G. (2017). Do the 'brain dead' merely appear to be alive? Journal of Medical Ethics, 43(11), 747-753.

Newton, J. D. (2011). How does the general public view posthumous organ donation? A meta-synthesis of the qualitative literature. BMC Public Health, 11(1), 791.

Nguyen, D. (2016). Brain death and true patient care. The Linacre Quarterly, 83(3), 258-282.

Oliver, M., Woywodt, A., Ahmed, A., \& Saif, I. (2010). Organ donation, transplantation and religion. Nephrology Dialysis Transplantation, 26, 437-444.

Oliver, M., Woywodt, A., Ahmed, A., \& Saif, I. (2011). Organ donation, transplantation and religion. Nephrology, Dialysis, Transplantation: Official Publication of the European Dialysis and Transplant Association - European Renal Association, 26(2), 437-444.

OPTN (Organ Procurement and Transplantation Network). (2020). Data. Retrieved July 26, 2020 from https://optn.transplant.hrsa.gov/data/.

Padela, A. I., Arozullah, A., \& Moosa, E. (2013). Brain death in Islamic ethico-legal deliberation: Challenges for applied Islamic bioethics. Bioethics, 27(3), 132-139.

Palma, P. (2017). Target low-cost kidney care. The Daily Star, February 02, 2017. Retrieved July 26, 2020, from https://www.thedailystar.net/frontpage/target-low-cost-kidney-care-1354768. 
Potter, K. (2017). Controversy in the determination of death: Cultural perspectives. Journal of Pediatric Intensive Care, 06(04), 245-247.

Prothom, A. (2020). First-ever cadaveric kidney transplant in Bangladesh in 'Mujib Borsho'. Prothom Alo English Desk, January 21, 2020. Retrieved July 26, 2020, from https://en.prothomalo.com/bangl adesh/First-ever-cadaveric-kidney-transplant-in.

Rady, M. Y., Verheijde, J. L., \& Ali, M. S. (2009). Islam and end-of-life practices in organ donation for transplantation: New questions and serious sociocultural consequences. HEC Forum, 21(2), 175-205.

Rahman, M., \& Mahmood, S. (2017). Status of organ donation and transplantation in Bangladesh. Transplantation. https://doi.org/10.1097/01.tp.0000525017.89355.1f.

Raho, J. A., Brown-Saltzman, K., Korenman, S. G., Weiss, F., Orentlicher, D., Lin, J. A., et al. (2019). Ethics of organ procurement from the unrepresented patient population. Journal of Medical Ethics, 45(11), 751-754.

Ralph, A. F., Alyami, A., Allen, R. D. M., Howard, K., Craig, J. C., Chadban, S. J., et al. (2016). Attitudes and beliefs about deceased organ donation in the arabic-speaking community in Australia: A focus group study. British Medical Journal Open, 6(1), 1-10.

Randell, T. T. (2004). Medical and legal considerations of brain death. Acta Anaesthesiologica Scandinavica, 48(2), 139-144.

Rashid, H. U. (2004). Health delivery system for renal disease care in Bangladesh. Saudi Journal of Kidney Diseases and Transplantation, 15(2), 185-189.

Rashid, H. U. (2014). Management of end stage renal disease-Bangladesh perspective. The Open Urology \& Nephrology Journal, 7, 108-112.

Rashid, H. U. (2018a). 4th national convention \& scientific seminar on oragn transplantation. In 4th national convention \& scientific seminar on oragn transplantation. Dhaka, pp. 1-2.

Rashid, H. U. (2018b). Address by president. In 4th national convention \& scientific seminar on organ transplantation. Society of Organ Transplantaion (SOT), Bangladesh.

Rassool, G. H. (2000). The crescent and Islam: Healing, nursing and the spiritual dimension. Some considerations towards an understanding of the Islamic perspectives on caring. Journal of Advanced Nursing, 32(6), 1476-1484.

Robson, N. Z., Haris, Md., Razack, A. H., \& Dublin, N. (2010). Review paper: Organ transplants: Ethical, social, and religious issues in a multicultural society. Asia-Pacific Journal of Public Health, 22(3), 271-278.

Rodríguez-Arias, D., Smith, M. J., \& Lazar, N. M. (2011). Donation after circulatory death: Burying the dead donor rule. The American Journal of Bioethics, 11(8), 36-43.

Sanal, A. (2005). Flesh yours, bones mine : The making of the biomedical subject in Turkey. Cambridge: Massachusetts Institute of Technology.

Al Sebayel, M. I. M., \& Khalaf, H. (2004). Knowledge and attitude of intensivists toward organ donation in Riyadh, Saudi Arabia. Transplantation Proceedings, 36(7), 1883-1884.

Shams, N. (2017). Saving lives through deceased organ donation. Herald, December 20, 2017. Retrieved July 26, 2020, from http://herald.dawn.com/news/1153939.

Sharifian, F., Dirven, R., Yu, N., \& Niemeier, S. (2008). Culture and language: Looking for the 'mind' inside the body. In F. Sharifian, R. Dirven, N. Yu, \& S. Niemeier (Eds.), Culture, body, and language: Conceptualizations of internal body organs across cultures and languages (pp. 3-24). Berlin: Walter de Gruyter.

Shroff, S. (2018). Challenges in setting up of a deceased donor transplant program in South Asia. Indian Journal of Transplantation, 12, 161-162.

Siraj, M. S. (2016). Organ donation for transplantation in Bangladesh: Policy, practice and ethics. Hong Kong: City University of Hong Kong.

Siraj, M. S., Dewey, R. S., \& Hassan, A. F. (2020). The infectious diseases act and resource allocation during the COVID-19 pandemic in Bangladesh. Asian Bioethics Review. https://doi.org/10.1007/ s41649-020-00149-9.

SNEDS. (2020). Eye donation. Retrieved July 17, 2020, https://www.snedsbd.org/default.php?id=donat ion.

Syed, J. (1998). Islamic views on organ donation. Journal of Transplant Coordination, 8(3), 157-163.

Tanim Anwar, A. S. M., \& Lee, J. M. (2019). Medical management of brain-dead organ donors. Acute and Critical Care, 34(1), 14-29.

ten Have, H., \& Gordijn, B. (2011). Travelling bioethics. Medicine, Health Care and Philosophy, 14(1), $1-3$. 
The Daily Star. (2020). 21 died on roads every day. The Daily Star, January 12, 2020. Retrieved August 05, 2020, from https://www.thedailystar.net/backpage/road-accident-in-bangladeh-21-died-every -day-1852867.

The Financial Express. (2020). Bangladesh awaits donors for first-ever kidney transplant from brain-dead. Naitonal, January 21, 2020. Retrieved July 26, 2020, from https://thefinancialexpress.com.bd/ public/national/bangladesh-awaits-donors-for-first-ever-kidney-transplant-from-brain-dead-15796 11352.

The Independent. (2020). Kidney donors can save 54 lives every day. The Independent BD, February 09, 2020. Retrieved July 26, 2020, from http://www.theindependentbd.com/post/236073.

The World Bank. (2017). Current health expenditure (\% of GDP). The World Bank Group. Retrieved August 21, 2020, from https://data.worldbank.org/indicator/SH.XPD.CHEX.GD.ZS.

The World Bank. (2019). Rural population (\% of total population)-Bangladesh. The World Bank. Retrieved October 8, 2020 from https://data.worldbank.org/indicator/SP.RUR.TOTL.ZS?locat ions $=$ BD.

Tober, D. M. (2007). Kidneys and controversies in the Islamic Republic of Iran: The case of organ sale. Body \& Society, 13(3), 151-170.

Truog, R. D. (2005). The ethics of organ donation by living donors. The New England Journal of Medicine, 353(5), 444-446.

Truog, R. D., Berlinger, N., Zacharias, R. L., \& Solomon, M. Z. (2018). Brain death at fifty: Exploring consensus, controversy, and contexts. Hastings Center Report, 48, S2-5.

Truog, R. D., Krishnamurthy, K., \& Tasker, R. C. (2020). Brain death-Moving beyond consistency in the diagnostic criteria. JAMA 324(11), 1045. https://doi.org/10.1001/jama.2020.11665.

Vathsala, A. (2004). Improving cadaveric organ donation rates in kidney and liver transplantation in Asia. Transplantation Proceedings, 36(7), 1873-1875.

Verheijde, J. L., Rady, M. Y., \& Potts, M. (2018). Neuroscience and brain death controversies: The elephant in the room. Journal of Religion and Health, 57(5), 1745-1763.

Smith, W. S. (2020). Standardizing brain death globally. JAMA Neurology. https://doi.org/10.1001/jaman eurol.2020.1243.

Wilkinson, T. M. (2005). Individual and family consent to organ and tissue donation: Is the current position coherent? Journal of Medical Ethics, 31(10), 587-590.

Wong, L. P. (2010). Factors limiting deceased organ donation: Focus groups' perspective from culturally diverse community. Transplantation Proceedings, 42(5), 1439-1444.

Wood, K. E., Becker, B. N., McCartney, J. G., D’Alessandro, A. M., \& Coursin, D. B. (2004). Care of the potential organ donor. New England Journal of Medicine, 351(26), 2730-2739.

Yeung, I., Kong, S. H., \& Lee, J. (2000). Attitudes towards organ donation in Hong Kong. Social Science and Medicine, 50(11), 1643-1654.

Zhang, K. (2020). The significance of physiological spaces in the body and its medical implications. Research, 2020, 1-10.

Publisher's Note Springer Nature remains neutral with regard to jurisdictional claims in published maps and institutional affiliations.

\section{Authors and Affiliations}

\section{Md. Sanwar Siraj ${ }^{1}$}

Md. Sanwar Siraj

siraj_sanwar@juniv.edu

1 Department of Government and Politics, Jahangirnagar University, Savar, Dhaka 1342,

Bangladesh 